Body region dissatisfaction predicts attention to body regions on other women Amy D. Lykins ${ }^{1,3}$, Tamara Ferris ${ }^{1}, \&$ Cynthia A. Graham ${ }^{2}$

${ }^{1}$ Discipline of Psychology, University of New England, Armidale, New South Wales, Australia

${ }^{2}$ Psychology Department, University of Southampton, Southampton, United Kingdom

${ }^{3}$ To whom correspondence should be addressed at the School of Behavioural Cognitive and Social Sciences, University of New England, Armidale NSW, Australia, 2351; Email: alykins@une.edu.au; Phone: +61 (2) 67735014.

Running Head: BODY IMAGE DISSATISFACTION AND ATTENTION 


\begin{abstract}
The proliferation of "idealized" (i.e., very thin and attractive) women in the media has contributed to increasing rates of body dissatisfaction among women. However, it remains relatively unknown how women attend to these images: does dissatisfaction predict greater or lesser attention to these body regions on others? Fifty healthy women (mean age $=21.8$ years) viewed images of idealized and plus-size models; an eye-tracker recorded visual attention. Participants also completed measures of satisfaction for specific body regions, which were then used as predictors of visual attention to these regions on models. Consistent with an avoidance-type process, lower levels of satisfaction with the two regions of greatest reported concern (mid, lower torso) predicted less attention to these regions; greater satisfaction predicted more attention to these regions. While this visual attention bias may aid in preserving self-esteem when viewing idealized others, it may preclude the opportunity for comparisons that could improve self-esteem.
\end{abstract}

Key Words: body image, eye-tracking, visual attention, body satisfaction, body dissatisfaction, women 


\section{Body region dissatisfaction predicts attention to body regions on other women}

Several meta-analyses of experimental studies have shown that exposure to media images of "idealized" (i.e., very thin and attractive) models contributes to body dissatisfaction in women (Grabe, Ward, \& Hyde, 2008; Groesz, Levine, \& Murnen, 2002), which, in turn, can contribute to other negative outcomes such as disordered eating, obesity, body dysmorphic disorder, depression, and low self-esteem (Dittmar, 2009; Glauert, Rhodes, Fink, \& Grammer, 2010; Littleton \& Ollendick, 2003). These relationships have been of particular interest due to the significant exposure to these idealized images many women experience (Fouts \& Burggraf, 1999, 2000; Greenberg, Eastin, Hofschire, Lachlan, \& Brownell, 2003; Richens, 1991). The underlying relationships among these variables (i.e., media exposure, body dissatisfaction, and other negative consequences) are undoubtedly complex; research exploring these mechanisms is needed but has been sparse (Tiggemann \& McGill, 2004).

Despite the primacy of visual material in these relationships, few studies have explored how women perceive or attend to images of other women using objective (non-selfreport) assessment of visual attention, such as eye-tracking, and how these patterns relate to women's own body image concerns. Ju and Johnson (2010) reported that women attended most to models in magazine advertisements, suggesting a prominence of visual appearancerelated information over other types of information (e.g., words). As evidenced by reaction time data, women selectively attended to thin women versus plus-size women regardless of body satisfaction (Glauert et al., 2010). In a study where women viewed images of themselves and others, healthy (i.e., non-eating-disordered) women attended most to others' "ugly" features, patterns which were reversed when they viewed themselves (Jansen, Nederkoorn, \& Mulkens, 2005). These results contrast somewhat with previous research on 
women both with and without eating disorders (Freeman et al., 1991; Richens, 1991), in which self-reported selective attention was highest to regions of personal dissatisfaction.

Comparison between the real self and the ideal, unattainable self has been proposed as a possible explanation for the negative consequences of media exposure to idealized women (Tiggemann \& McGill, 2004). Social comparison theory (Festinger, 1954) maintains that individuals compare themselves with others for purposes of self-evaluation. "Upward" comparisons occur when individuals compare themselves to someone perceived to be more desirable than themselves; the dissonance between the real and ideal self experienced can provoke body dissatisfaction and disordered eating resulting from the inability (either real or perceived) to attain the desired traits (Richens, 1991; Tiggemann \& McGill, 2004). In contrast, "downward" comparisons occur when individuals compare themselves with people they consider to be less desirable or fortunate than themselves, often resulting in increased positive mood associated with a positive evaluation of oneself in comparison to others. Consistent with this theory, research has indicated that viewing plus-size women induces positive effects on women's body image (Halliwell \& Dittman, 2004; Owen \& Spencer, 2013).

Visual attention to images of differently-sized women offers an interesting test of social comparison theory: consistent with some self-report data, do women actually attend to body regions of personal concern when viewing other women? Furthermore, are viewing patterns affected by whether someone is theoretically engaging in upward comparisons (e.g., viewing idealized models) vs. downward comparisons (e.g., viewing plus-size models)? Consistent with self-report data, we hypothesized that participants would show preferential attention to regions of personal dissatisfaction when viewing the idealized models and would show less interest in these same regions when viewing the plus-size models.

\section{Method}




\section{Participants}

Fifty women $(M=21.8$ years, $S D=3.03$, range 18 - 30 years $)$, a typical sample size for eye-tracking studies, were recruited from a regional Australian university. Consistent with the university's typical demographics, participants were predominantly Caucasian (90\%) and heterosexual (98\%, 2\% bisexual). Two participants reported a history of disordered eating. As results did not differ in analyses run both with and without these two participants, they were included in all analyses. The study was advertised as an assessment of body image in young women. Participants who were enrolled in Introductory Psychology or part of a university awards scheme received credit for participation; no other compensation was offered.

\section{Measures}

Demographic questionnaire. Participants completed a demographics questionnaire, which included questions about age, ethnicity, sexual orientation, current level of education, and history of eating disorder(s).

Multidimensional Body-Self Relations Questionnaire (MBSRQ; Brown, Cash, \& Mikulka, 1990; Cash, 2000). The MBSRQ has been reported as a valid and reliable measure of trait body image in previous studies (see Cash, 2000). The Body Areas Satisfaction Scale (BASS) subscale, including items on personal satisfaction with specific body regions, was used in this study. The BASS comprises nine items, but we analyzed only the five that were defined physical body regions: hair, face, upper torso (including arms), mid torso (waist-hip region), and lower torso (including legs). Each region was rated on a 5-point scale, with lower scores indicating greater dissatisfaction. In a test sample of college women (Cash, 2000), Cronbach's alpha was .73 (with a one-month follow-up of .74); the Cronbach's $\alpha$ for the 5 items used in the current study was .56 (for all 9 items, Cronbach's $\alpha$ was .77). 
Visual stimuli. Two sets of images were compiled, each with six images of women estimated to be between 18 and 30 years. One group contained images of typical models that were very slim (referred to as "idealized" models); the other group contained images of women who would typically be considered to be "plus-size." All images were sourced from online stores for swimwear. A collection of appropriate models was reviewed by independent raters to ensure all models' faces were rated as equally attractive ${ }^{1}$ and to eliminate any models who were recognizable. Care was taken in selecting and matching the final selection of images to ensure the models were similar on as many dimensions as possible other than their weight. All models were Caucasian, had attractive faces, long brunette hair, were smiling, wore one-piece swimsuits, and stood in similar poses against equally nondescript backgrounds. To reduce attention related to visual features rather than content, swimsuits were matched relative to patterns and brightness of colors.

\section{Apparatus}

Eye movements were recorded using an Applied Science Laboratories (ASL) D6 eyetracker, with optics designed to accurately measure a person's point of gaze on a stationary (room fixed) scene space. This eye tracker utilizes the corneal reflection method, a more accurate method than simply tracking the pupil alone because the computer tracks two points of reference rather than just one. The GazeTracker program presented the stimuli and synchronized and recorded the eye movement data. Stimuli were presented on a Plug and Play Dell monitor on Intel(R) 4 Series Internal Chipset, with a screen resolution of $1024 \mathrm{x}$ 768 pixels, and operating with a screen refresh rate of $75 \mathrm{~Hz}$.

\section{Procedure}

After providing informed consent, participants completed the MBSRQ. The eyetracker was then set up and calibrated to ensure that eye movements would be tracked reliably. Each image was presented for eight seconds, followed by a 3-second buffer slide to 
direct all participants' attention back to the same starting point prior to each stimulus image. Instructions were simply to "look as you normally would." For data analysis, each image was divided into five scene regions corresponding to the five BASS body regions. The dependent measure of interest was total gaze time (the total amount of time in milliseconds each participant spent looking at each individual scene region in each image; this was then averaged across all stimuli of the same category); this has been identified as a reliable and valid measure of overall interest in a scene region (Henderson \& Hollingworth, 1999). The university's Human Research Ethics Committee approved the study.

\section{Results}

Participants reported the highest level of dissatisfaction with their mid- $(M=2.55, S D$ $=1.12)$ and lower torsos $(M=2.84, S D=1.12)$, followed by their faces $(M=3.41, S D=$ $0.84)$, upper torsos $(M=3.67, S D=1.01)$, and hair $(M=3.90, S D=0.96)$. Multiple regression analyses were conducted to assess whether body region satisfaction predicted attention to those body regions while viewing idealized and plus-size women (see Tables 1 and 2). The overall regression models significantly predicted attention to the mid torso on the idealized women, Adjusted $R^{2}=.84, F(5,40)=44.35, p<.001$, and on the plus-size women, Adjusted $R^{2}=.17, F(5,40)=2.48, p=.05$. Participants' satisfaction with their mid torsos predicted attention to this region on both idealized $(p=.01)$ and plus-size $(p<.001)$ women. The overall regression models also significantly predicted attention to the lower torso on the idealized women, Adjusted $R^{2}=.86, F(5,40)=51.53, p<.001$, and on the plus-size women, Adjusted $R^{2}=.22, F(5,40)=3.22, p=.02$. Satisfaction with one's own lower torso also predicted attention to this region for both idealized $(p<.001)$ and plus-size $(p=.001)$ models. Thus, dissatisfaction with the two regions of greatest reported concern (mid and lower torso) predicted attention to these regions on images of both idealized and plus-size 
models. Lower levels of satisfaction with these regions predicted less attention, whereas greater satisfaction predicted more attention, to these regions.

Insert Table 1 about here

Insert Table 2 about here

\section{Discussion}

Social comparison of physique and attractiveness has been proposed as an explanation for why women look at other women, and may underlie the link between exposure to media images of idealized women and subsequent negative effects (e.g., poor body image, eating disorders). As such, it is reasonable to posit that a woman's satisfaction with specific regions of her body might predict attention to these regions on others, providing evidence of this comparison process. Our findings indicate that satisfaction with one's body did predict attention toward those areas on others, at least for the two areas of greatest concern (mid and lower torso). However, somewhat contrary to the comparison hypothesis, only women reporting greater satisfaction with these two regions showed more attention to them; women reporting lower satisfaction with these regions attended less to these regions. Interestingly, these results were the same for attention to both images of idealized and plus-size women.

These results partially replicate one previous study (Janelle, Hausenblas, Fallon, \& Gardner, 2003), but contrast with those of several other studies (Jansen et al., 2005; Richens, 1991), which have suggested a hypervigilance to specific areas of dissatisfaction. Our findings indicate the opposite - relative avoidance of attention to these areas. Perhaps most 
intriguing is that this avoidance occurred when looking at both the idealized and the plus-size models. In order to preserve self-esteem, social comparison theory (Festinger, 1954) would predict that individuals engaging in "upward" comparisons to idealized others might avoid areas of personal concern, whereas those engaging in "downward" comparisons might preserve self-esteem by attending more to these areas (due to the positive contrast between themselves and others to whom they do not aspire). However, we found this same relative inattention to these areas of dissatisfaction when participants viewed both idealized and plussize models. Thus, it may be that women's dissatisfaction of their own body regions "trumps" any potential for downward comparison when looking at non-idealized women. Perhaps women have learned to avoid attending to these regions on other women (regardless of the other's appearance) in order to preserve self-esteem.

Several studies have demonstrated that when individuals are presented with images related to their personal concerns, they often show global avoidance of them (Amir, Elias, Klumpp, \& Przeworski, 2003; Lykins, Meana, \& Minimi, 2011; Miltner, Krieschel, Hecht, Trippe, \& Weiss, 2004). These viewing patterns likely represent a typical anxiety response, whereby individuals generally avoid looking at anxiety-provoking stimuli (Rinck \& Becker, 2006). This same type of anxiety response may be occurring in women who experience body dissatisfaction, creating an avoidance of stimuli that reinforces their body concerns. Ironically, this type of avoidance may preclude the possibility of downward comparisons that may enhance self-esteem.

The fact that our results were somewhat unanticipated may be due to one (or more) factors. First, most previous research has targeted women with significant body image issues and/or eating disorder pathology. Our findings on psychologically healthy women seem to suggest that they are employing self-esteem-preserving strategies when viewing female models rather than focusing on body regions of concern. Perhaps this difference in 
preferential attention is one of the factors that differentiate those who fall into clinical or healthy groups. Second, many previous studies have utilized self-report methodology, relying on women to accurately report what they are attending to; however, non-self-report methodology is the only way to assess whether individuals are reporting their behavior accurately. Given the current results, it seems likely that they are not, although it is possible that participants' attention may have been influenced by knowing that their eye movements were being recorded. Inconsistencies between what women report attending to versus what they actually attend to may reflect a memory bias for information that spurred a stronger emotional response (i.e., negative affect when viewing regions of dissatisfaction) rather than an actual attentional bias. Lastly, most previous research has examined global body image related to whole body images of models; breaking these body regions down in both instances results in more sensitive, specific data that would not be assessable by more general measures.

Strengths of this study include a well-controlled set of stimuli and participant selection, the assessment of satisfaction with specific body regions rather than global body satisfaction, and the use of a validated and reliable measure of visual attention. Several limitations are worth noting. In aiming to control for variables that might have affected our data, our visual stimuli (i.e., models) and participants were somewhat homogenous. Future research could expand the diversity of stimuli and participants (including men and clinical samples of women) to see if similar patterns are found. Future studies might also obtain participants' self-perception of what they most/least attended to (and why) to test the above hypothesis of comparison and/or anxiety with self-report data. The completion of the MBSRQ should be counterbalanced, with an equal number of participants completing it before and after presentation of images (in case the completion of this measure primed viewing). Future research could include measures of media use and individual propensity for 
social comparison to assess whether these factors may account for variance or mediate/moderate results in some way. Furthermore, exploring ways in which the impact of viewing idealized models might be attenuated (e.g., Yamamiya et al., 2005) via visual attention means may be beneficial. Lastly, it may be useful to assess not only self-reported body image but actual body composition (e.g., BMI) and see how this variable relates to visual attention to other women.

To our knowledge, this is the first study to look at satisfaction with specific body regions (as opposed to overall body satisfaction) and visual attention to these body regions on both idealized and plus-size women. The findings are also important because they add to a growing body of literature examining not just women with diagnosed eating disorders, but also women without eating disorders who similarly experience exposure to media images of idealized women. 


\section{Footnotes}

${ }^{1}$ Ratings for the idealized models $(M=7.46, S D=1.35)$ and the plus-size models $(M=7.59$, $S D=1.20)$ were not significantly different, $F(1,136)=0.36, p=0.55$. 


\section{References}

Amir, N., Elias, J., Klumpp, H., \& Przeworski, A. (2003). Attentional bias to threat in social phobia: Facilitated processing of threat or difficulty disengaging attention from threat? Behaviour Research and Therapy, 41, 1325-1335. doi: 10.1016/S0005-7967(03)00039-1

Brown, T. A., Cash, T. F., \& Mikulka, P. J. (1990). Attitudinal body-image assessment: Factor analysis of the Body-Self Relations Questionnaire. Journal of Personality Assessment, 55, 135-144. doi: 10.1080/00223891.1990.9674053

Cash, T. F. (2000). User's manual for the Multidimensional Body-Self Relations Questionnaire. Available from the author at www.body-images.com.

Dittmar, H. (2009). How do "body perfect" ideals in the media have a negative impact on body image and behaviours? Factors and processes related to self and identity. Journal of Social and Clinical Psychology, 28, 1-8. doi: 10.1521/jscp.2009.28.1.1

Festinger, L. (1954). A theory of social comparison processes. Human Relations, 7, 117-140. doi: $10.1177 / 001872675400700202$

Fouts, G., \& Burggraf, K. (1999). Television situational comedies: Female body images and verbal reinforcement. Sex Roles, 40, 473-481. doi: 10.1023/A:1018875711082

Fouts, G., \& Burggraf, K. (2000). Television situational comedies: Female weight, male negative comments, and audience reactions. Sex Roles, 42, 925-932. doi: 10.1023/A:1007054618340

Freeman, R., Touyz, S., Sara, G., Rennie, C., Gordon, E., \& Beumont, P. (1991). In the eye of the beholder: Processing body shape information in anorexic and bulimic patients. International Journal of Eating Disorders, 10, 709-714. doi: 10.1002/1098-108X(199111)10:6<709::AID-EAT2260100609>3.0.CO;2-N

Glauert, R., Rhodes, G., Fink, B., \& Grammer, K. (2010). Body dissatisfaction and 
attentional bias to thin bodies. International Journal of Eating Disorders, 43, 42-49. doi: 10.1002/eat.20663

Grabe, S., Ward, L. M., \& Hyde, J. S. (2008). The role of the media in body image concerns among women: A meta-analysis of experimental and correlational studies. Psychological Bulletin, 134, 460-476. doi: 10.1037/0033-2909.134.3.460

Greenberg, B. S., Eastin, M., Hofschire, L., Lachlan, K., \& Brownell, K. (2003). Portrayals of overweight and obese individuals on commercial television. American Journal of Public Health, 93, 1342-1348. doi: 10.2105/AJPH.93.8.1342

Groesz, L. M., Levine, M. P., \& Murnen, S. K. (2002). The effect of experimental presentation of thin media images on body satisfaction: A meta-analytic review. International Journal of Eating Disorders, 31, 1-16. doi: 10.1002/eat.10005

Halliwell, E., \& Dittmar, H. (2004). Does size matter? The impact of model's body size on women's body-focused anxiety and advertising effectiveness. Journal of Social and Clinical Psychology, 23, 104-122. doi: 10.1521/jscp.23.1.104.26989

Henderson, J. M., \& Hollingworth, A. (1999). High-level scene perception. Annual Review of Psychology, 50, 243-271. doi: 10.1146/annurev.psych.50.1.243

Janelle, C. M., Hausenblas, H. A., Fallon, E. A., \& Gardner, R. E. (2003). A visual search examination of attentional biases among individuals with high and low drive for thinness. Eating and Weight Disorders, 8, 138-144. doi: 10.1007/BF03325003

Jansen, A., Nederkoorn, C., \& Mulkens, S. (2005). Selective visual attention for ugly and beautiful body parts in eating disorders. Behaviour Research and Therapy, 43, 183196. doi: 10.1016/j.brat.2004.01.003

Ju, H. W., \& Johnson, K. K. P. (2010). Fashion advertisements and young women: Determining visual attention using eye tracking. Journal of Clothing Textiles Research, 28, 159-173. doi: 10.1177/0887302X09359935 
Littleton, H. L., \& Ollendick, T. (2003). Negative body image and disordered eating behaviour in children and adolescents: What places youth at risk and how can these problems be prevented? Clinical Child and Family Psychology Review, 6, 51-66. doi: 10.1023/A:1022266017046

Lykins, A. D., Meana, M., \& Minimi, J. (2010). Visual attention to erotic images in women reporting pain with intercourse. Journal of Sex Research, 48, 43-52. doi: $10.1080 / 00224490903556374$

Miltner, W. H. R., Krieschel, S., Hecht, H., Trippe, R., \& Weiss, T. (2004). Eye movements and behavioral responses to threatening and nonthreatening stimuli during visual search in phobic and nonphobic subjects. Emotion, 4, 323-339.

Owen, R., \& Spencer, R. M. C. (2013). Body ideals in women after viewing images of typical and healthy weight models. Body Image, 10, 489-494. doi: 10.1016/j.bodyim.2013.04.005

Richins, M. L. (1991). Social comparison and the idealised images of advertising. Journal of Consumer Research, 18, 71-83.

Rinck, M., \& Becker, E. S. (2006). Spider fearful individuals attend to threat, then quickly avoid it: Evidence from eye movements. Journal of Abnormal Psychology, 115, 231238. doi: 10.1037/0021-843X.115.2.231

Tiggemann, M., \& McGill, B. (2004). The role of social comparison in the effect of magazine advertisements on women's mood and body dissatisfaction. Journal of Social and Clinical Psychology, 23, 23-44. doi: 10.1521/jscp.23.1.23.26991

Yamamiya, Y., Cash, T. F., Melnyk, S. E., Posavac, H. D., \& Posavac, S. S. (2005). Women's exposure to thin-and-beautiful media images: Body image effects of media-ideal internalization and impact-reduction interventions. Body Image, 2, 74-80. doi: 10.1016/j.bodyim.2004.11.001 
Table 1. Descriptive Data and Multiple Regression Analyses Predicting Attention to Specific

Means and Standard Deviations for Gaze Time (in seconds) on Specific Body Regions

\begin{tabular}{ll}
\hline Body region & Mean $(\mathrm{SD})$ \\
\hline Hair & $0.24(0.34)$ \\
Face & $1.66(1.22)$ \\
Upper torso & $2.88(1.05)$ \\
Mid torso & $0.57(0.38)$ \\
Lower torso & $0.76(0.47)$ \\
\hline
\end{tabular}

\begin{tabular}{|c|c|c|c|c|c|c|}
\hline \multirow[b]{2}{*}{ Predictor } & \multirow[b]{2}{*}{$B$} & \multicolumn{2}{|c|}{$C I_{95 \%}$ for $B$} & \multirow[b]{2}{*}{$\beta$} & \multirow[b]{2}{*}{$r$} & \multirow[b]{2}{*}{$s r$} \\
\hline & & Lower & Upper & & & \\
\hline \multicolumn{7}{|c|}{ Attention to hair } \\
\hline Hair & -0.03 & -0.11 & 0.05 & -0.15 & -.20 & -.13 \\
\hline Face & 0.01 & -0.07 & 1.10 & 0.06 & .03 & .05 \\
\hline Upper torso & 0.06 & -0.01 & 0.12 & 0.29 & .30 & .27 \\
\hline Mid torso & -0.08 & -0.33 & 0.16 & -0.12 & -.13 & -.11 \\
\hline Lower torso & -0.02 & -0.27 & 0.23 & -0.03 & -.04 & -.03 \\
\hline \multicolumn{7}{|c|}{ Attention to face } \\
\hline Hair & -0.09 & -0.56 & 0.38 & -0.07 & -.08 & -.06 \\
\hline Face & 0.12 & -0.40 & 0.64 & 0.08 & -.04 & .07 \\
\hline Upper torso & 0.28 & -0.69 & 0.13 & -0.23 & -.26 & -.22 \\
\hline Mid torso & -0.81 & -1.98 & 0.97 & -0.12 & -.20 & -.17 \\
\hline Lower torso & -0.51 & -2.32 & 0.70 & -0.19 & -.28 & -.11 \\
\hline \multicolumn{7}{|c|}{ Attention to upper torso } \\
\hline Hair & -0.06 & -0.46 & 0.33 & 0.06 & .02 & -.05 \\
\hline Face & 0.14 & -0.31 & 0.58 & -0.15 & .01 & .10 \\
\hline Upper torso & -0.27 & -0.62 & 0.08 & 0.29 & -.20 & -.24 \\
\hline Mid torso & -0.19 & -2.43 & 0.06 & -0.12 & -.25 & -.30 \\
\hline Lower torso & 1.13 & -0.14 & 0.23 & 2.41 & .15 & .28 \\
\hline \multicolumn{7}{|c|}{ Attention to mid torso } \\
\hline Hair & -0.12 & -0.25 & 0.03 & -0.27 & -.08 & -.23 \\
\hline Face & 0.02 & -0.13 & 0.18 & 0.05 & .05 & .04 \\
\hline Upper torso & -0.03 & -0.15 & 0.09 & -0.08 & .05 & -.08 \\
\hline Mid torso & $0.55 * *$ & -0.12 & 0.98 & 0.41 & .42 & .38 \\
\hline Lower torso & 0.32 & 0.12 & 0.76 & 0.24 & .29 & .21 \\
\hline \multicolumn{7}{|c|}{ Attention to lower torso } \\
\hline Hair & -0.08 & -0.24 & 0.08 & -0.17 & .06 & .14 \\
\hline Face & 0.05 & -0.13 & 0.23 & 0.08 & .09 & .07 \\
\hline Upper torso & -0.08 & -0.22 & 0.06 & -0.17 & -.01 & -.16 \\
\hline Mid torso & 0.23 & -0.27 & 0.74 & 0.14 & .28 & .13 \\
\hline Lower torso & $0.88 * * *$ & 0.36 & 1.40 & 0.54 & .52 & .48 \\
\hline
\end{tabular}

Body Regions of the Idealized Models with Satisfaction Ratings of Participants' Own Body Regions 
Note. Predictor values are the individual scores for corresponding items of the BASS. Higher scores indicate higher satisfaction. Attention measured by mean total time in scene region (seconds).

$* p<.05, * * p<.01, * * * p<.001$.

Table 2. Descriptive Data and Multiple Regression Analyses Predicting Attention to Specific Body Regions of the Plus-Size Models with Satisfaction Ratings of Participants' Own Body Regions

Means and Standard Deviations for Gaze Time (in seconds) on Specific Body Regions

\begin{tabular}{ll}
\hline Body region & Mean $(\mathrm{SD})$ \\
\hline Hair & $0.31(0.30)$ \\
Face & $1.61(1.20)$ \\
Upper torso & $3.24(1.09)$ \\
Mid torso & $0.69(0.51)$ \\
Lower torso & $0.66(0.40)$ \\
\hline
\end{tabular}

Multiple Regression Results

\begin{tabular}{|c|c|c|c|c|c|c|}
\hline \multirow[b]{2}{*}{ Predictor } & \multirow[b]{2}{*}{$B$} & \multicolumn{2}{|c|}{$C I_{95 \%}$ for $B$} & \multirow[b]{2}{*}{$\beta$} & \multirow[b]{2}{*}{$r$} & \multirow[b]{2}{*}{$s r$} \\
\hline & & Lower & Upper & & & \\
\hline \multicolumn{7}{|c|}{ Attention to hair } \\
\hline Hair & 0.06 & -0.04 & 0.15 & 0.22 & .08 & .19 \\
\hline Face & 0.01 & -0.09 & 0.11 & 0.04 & .04 & .03 \\
\hline Upper torso & 0.03 & -0.06 & 0.10 & 0.10 & .00 & .10 \\
\hline Mid torso & -0.25 & -0.54 & 0.03 & -0.30 & -.32 & -.27 \\
\hline Lower torso & -0.23 & -0.52 & 0.06 & -0.27 & -.29 & -.24 \\
\hline \multicolumn{7}{|c|}{ Attention to face } \\
\hline Hair & -0.27 & -0.70 & 0.15 & -0.24 & -.20 & -.21 \\
\hline Face & 0.24 & -0.23 & 0.71 & 0.18 & .03 & .16 \\
\hline Upper torso & -0.18 & -0.55 & 0.20 & -0.16 & -.14 & -.15 \\
\hline Mid torso & -0.26 & -1.60 & 1.07 & -0.07 & -.16 & -.06 \\
\hline Lower torso & -0.61 & -1.97 & 0.76 & -0.16 & -.25 & -.14 \\
\hline \multicolumn{7}{|c|}{ Attention to upper torso } \\
\hline Hair & 0.25 & -0.19 & 0.68 & 0.22 & .09 & .19 \\
\hline Face & -0.17 & -0.65 & 0.32 & -0.13 & -.08 & -.11 \\
\hline Upper torso & 0.06 & -0.33 & 0.44 & 0.05 & -.05 & .05 \\
\hline Mid torso & -0.43 & -1.80 & 0.95 & -0.11 & -.14 & -.10 \\
\hline Lower torso & -0.65 & -2.05 & 0.75 & -0.17 & -.16 & -.15 \\
\hline \multicolumn{7}{|c|}{ Attention to mid torso } \\
\hline Hair & 0.01 & -0.05 & 0.06 & 0.01 & .16 & .01 \\
\hline Face & $-0.09 *$ & -0.15 & -0.02 & -0.19 & .02 & -.17 \\
\hline Upper torso & 0.02 & -0.03 & 0.07 & 0.06 & .12 & .06 \\
\hline Mid torso & $1.23 * * *$ & 1.05 & 1.41 & 0.93 & .91 & .86 \\
\hline Lower torso & 0.04 & -0.15 & 0.22 & 0.03 & .32 & .02 \\
\hline \multicolumn{7}{|c|}{ Attention to lower torso } \\
\hline Hair & -0.06 & -0.11 & 0.00 & -0.13 & .16 & -.11 \\
\hline Face & 0.01 & -0.06 & 0.07 & 0.02 & .14 & .02 \\
\hline Upper torso & -0.01 & -0.06 & 0.04 & -0.02 & .20 & -.02 \\
\hline Mid torso & $0.44 *$ & 0.26 & 0.64 & 0.31 & .55 & .29 \\
\hline
\end{tabular}


$\begin{array}{lcccccc}\text { Lower torso } & 1.16^{* * *} & 0.98 & 1.35 & 0.82 & .89 & .74\end{array}$ scores indicate higher satisfaction. Attention measured by mean total time in scene region (seconds). There were no significant differences in attention between the idealized and plussize models to any of the body regions (all $p$ 's $>.05$ ).

$* p<.05, * * p<.01, * * * p<.001$. 